\title{
RELAÇÃO OBRIGACIONAL COMO \\ Processo na ConstruÇão do PARADIGMA dOS DEVERES GERAIS DE CONDUTA E SUAS CONSEQUÊNCIAS
}

\author{
OBLIGATIONAL RELATIONSHIP AS \\ PROCESS IN THE CONSTRUCTION OF THE PARADIGM OF THE \\ GENERAL DUTIES OF CONDUCT AND ITS CONSEQUENCES
}

Marcos Ehrhardt Júnior*

RESUMO: A partir da perspectiva do direito civil constitucional o texto procura demonstrar que o conceito clássico de relação obrigacional se revelou inadequado e insuficiente para tutelar todas as vicissitudes inerentes à visão solidarista da relação obrigacional, que não mais se limita ao resultado da soma de débito e crédito, devendo abandonar tal posição estática para que o vínculo obrigacional seja visto como um processo de cooperação voltado para determinado fim.

PALAVRAS-CHAVE: Relação Jurídica. Obrigação como processo. Deveres Gerais de Conduta.

ABSTRACT: From the perspective of civil law constitutional text argues that the classical concept of obligational relationship proved inadequate and insufficient to protect all the demands inherent in the relationship obligational solidarist view, no longer merely the result of the sum of debt and credit, and must abandon this static position for the bond to be seen as an obligational cooperation process aimed at an end.

KEYWORDS: Legal relationship. Obligation as a process. General Duties of Conduct.

* Advogado. Doutor pela Universidade Federal de Pernambuco (UFPE). Mestre pela Universidade Federal de Alagoas (UFAL). Professor de Direito Civil da UFAL, dos Cursos de Pós-Graduação da UFPE, do Centro Universitário CESMAC e da Escola Superior da Magistratura em Pernambuco (ESMAPE). Coordenador da Revista Fórum de Direito Civil. Integrante do Grupo de Pesquisa Constitucionalização das Relações Privadas. E-mail: marcosehrhardtjr@uol.com.br 


\section{A RELAÇÃO JURÍdica OBRIGACIONAL EM SUA PERSPECTIVA TRADICIONAL}

Partindo da análise do direito desde sua origem no fenômeno social, da interação entre os sujeitos, vislumbra-se a relação jurídica como uma das mais importantes categorias da teoria geral do direito. Entre os tratadistas tradicionais existe uma certa uniformidade na delimitação do conceito de relação jurídica obrigacional, bem caracterizado na lição de Arnaldo Rizzardo (2006, p. 4), que define obrigação como uma relação pela qual "alguém deve cumprir determinada prestação em favor de outrem. Ou sujeita-se o devedor a uma determinada prestação em prol do credor".

Para Sílvio Rodrigues (2002, p. 3-4), obrigação é o vínculo de direito pelo qual alguém (sujeito passivo) se propõe a dar, fazer ou não fazer qualquer coisa (objeto), em favor de outrem (sujeito ativo). Conservando a mesma orientação, Caio Mário da Silva Pereira (2009, p. 3-4) destaca que "o recurso à etimologia é bom subsídio: obrigação, do latim ob + ligatio, contém uma ideia de vinculação, de liame, de cerceamento da liberdade de ação, em benefício de pessoa determinada ou determinável"1.

Todos os autores citados ressaltam em seus escritos o caráter transitório e econômico da relação, uma vez que seu adimplemento é garantido mediante o patrimônio do devedor, razão pela qual Orlando Gomes (2004, p. 17) sustentava que, encarada em seu conjunto, a relação obrigacional é "um vínculo jurídico entre duas partes, em virtude do qual uma delas fica adstrita a satisfazer uma prestação patrimonial de interesse da outra, que pode exigi-la, se não for cumprida espontaneamente, mediante agressão ao patrimônio do devedor"2.

Sob esse prisma, estudar a relação obrigacional, a partir do seu disciplinamento no Código Civil, significa apenas analisar seus elementos constitutivos, razão pela qual se distinguem o (a) elemento subjetivo, vale dizer, os sujeitos da relação jurídica (sujeito ativo ou credor e sujeito passivo ou devedor); (b) o elemento objetivo ou material, relativo ao seu objeto, que pode ser deduzido numa prestação de fazer, não fazer ou de dar, e o (c) vínculo jurídico, também denominado elemento imaterial, abstrato ou espiritual, que seria justamente o elemento que confere ao credor o direito de exigir do devedor o cumprimento da obrigação (GONÇALVES, 2009, p. 23).

1 Prossegue o referido autor destacando a ideia de vinculação presente desde os Romanos: "obligatio est iuris vinculum quo necessitate adstringimur, alicuius solvendae rei, secundum nostrae civitalis iura" (Institutas, Livro III, tít. 14).

2 Para Washington de Barros Monteiro (2003, p. 8), "obrigação é a relação jurídica, de caráter transitório, estabelecida entre devedor e credor e cujo objeto consiste numa prestação pessoal econômica, positiva ou negativa, devida pelo primeiro ao segundo, garantindo-lhe o adimplemento através de seu patrimônio". Já Antunes Varela (1977, p. 58) afirma que "obrigação consiste na relação jurídica por virtude da qual uma pessoa pode exigir, no seu interesse, determinada prestação de uma outra, ficando esta vinculada ao correspondente dever de prestar". 
Desse modo, a relação jurídica obrigacional, em sentido amplo, apresenta dupla face: é um elemento ativo do patrimônio do credor e um elemento passivo do patrimônio do devedor. $\mathrm{O}$ que permite afirmar que "ao direito corresponde o dever, que tem por objeto a prestação" (LÔBO, 2011, p. 28-9). Por outro lado, em sentido estrito, tem-se obrigação como o dever (dívida) que pode ser exigido pelo credor.

Analisando a relação jurídica obrigacional pela óptica da teoria do fato jurídico, pode-se afirmar que o direito subjetivo é aquilo que resulta da incidência da norma com a formação do fato jurídico, que deixa um sujeito em relação de vantagem quanto a outro sujeito que, de forma correspectiva, tem um dever subjetivo (CATÃO, 2002). Dessa forma, surge um direito subjetivo quando, por exemplo, celebra-se um determinado negócio jurídico que permite ao sujeito satisfazer um interesse juridicamente protegido. Normalmente há, no conteúdo eficacial da relação jurídica, além do direito, a pretensão de um sujeito, que corresponde à obrigação do outro.

Em outras palavras, no direito obrigacional o credor (sujeito ativo) é aquele que tem a faculdade, reconhecida pelo sistema jurídico, de exigir do devedor (sujeito passivo) uma prestação, isto é, a realização de uma conduta, que se manifesta pelo exercício de uma obrigação de dar, fazer ou não fazer.

Dito de outro modo: "pretensão é a posição subjetiva de poder exigir de outrem alguma prestação positiva ou negativa" (PONTES DE MIRANDA, 1972, p. 52) ${ }^{3}$; quer dizer, portanto, exigibilidade, ou seja, faculdade de se cobrar de outrem a satisfação de um interesse juridicamente reconhecido e protegido pelo ordenamento ${ }^{4}$.

Pontes de Miranda (1984, p. 12), preocupado com a precisão dos conceitos, sustenta que "quem deve está em posição de ter o dever de adimplir. Pode não estar obrigado a isso. Então há o dever, e não há obrigação. (...) Crédito sem pretensão é crédito mutilado (...) Existe o crédito, porém não se pode exigir".

Numa relação jurídica obrigacional, não pode existir obrigação sem dívida (dever), que por sua vez não pode ser confundida com a prestação, porque esta é o objeto daquela. Vale anotar que o objeto da prestação não é a coisa em si, mas uma ação ou omissão do devedor, isto é, um dar, fazer ou não fazer.

3 Razão pela qual Marcos Bernardes de Mello (2007, p. 183) afirma que a pretensão “constitui o grau de exigibilidade do direito (subjetivo) e a obrigação de submissão ao adimplemento".

4 Vale aqui transcrever advertência de Paulo Lôbo (2011, p. 50): “A doutrina costuma identificar a relação jurídica obrigacional na exigibilidade da prestação, ou seja, é aquela em que uma parte tem o direito de exigir uma determinada prestação e a outra tem a obrigação de cumpri-la. Mas a exigibilidade é desdobramento ou efeito da relação de crédito e débito, quando o primeiro se converte em pretensão e o segundo em obrigação em sentido estrito (...) Não se pode enxergar a relação obrigacional apenas quando a dívida se convolou em obrigação, ou quando o dever de prestar já é exigível". 
Do mesmo modo, e considerando os fins do presente trabalho, imperioso distinguir dívida de responsabilidade ${ }^{5}$. Tem-se a dívida (débito, dever) como o correlativo do direito do credor. Desse modo, pode o devedor, pela obrigação, responder com seu patrimônio ou parte dele, já que a responsabilidade não é pessoal, afetando-se apenas o patrimônio do sujeito passivo - e não sua liberdade - para a satisfação da dívida, desde que não se comprometa o mínimo necessário à existência da pessoa humana ${ }^{6}$.

No entanto, a unidade do direito das obrigações não está mais enraizada exclusivamente nos códigos civis, mas também no conjunto de princípios e regras que se elevaram à Constituição, em torno dos quais gravitam os microssistemas jurídicos que tratam das matérias a ele vinculadas (LÔBO, 2011, p. 18).

Por essa razão, há de se considerar o texto constitucional como ápice conformador da elaboração e aplicação da legislação civil ao propiciar unidade hermenêutica ${ }^{7} \mathrm{em}$ relação a espaços até então considerados distintos e, por vezes, contrapostos (LÔBO, 2011, p. 18), o que leva Paulo Luiz Netto Lôbo (2011, p. 18) às seguintes conclusões:

Extrai-se da Constituição brasileira, em razão dos valores incorporados em suas normas, que, no plano geral do direito das obrigações convencionais, o paradigma liberal de prevalência do interesse do credor e do antagonismo foi substituído pelo equilíbrio de direitos e deveres entre credor e devedor, não apenas na dimensão formal, da tradição dos juristas, mas, sobretudo, na dimensão da igualdade ou equivalência material, fundado no princípio da solidariedade social.

Considerando o disposto nos parágrafos anteriores, pode-se concluir que o conceito clássico de relação obrigacional ${ }^{8}$ se revelou inadequado e insuficiente para tutelar todas

5 O tema da distinção entre dívida $\mathrm{x}$ responsabilidade frequentemente é retratado utilizando-se termos sinônimos. Há quem prefira schuld, debitum, duty ou devoir para se referir à dívida, enquanto a noção de responsabilidade é apresentada sob a denominação de haftung, obligatio, liability ou engagement.

6 Como bem anota Luiz Edson Fachin (2006, p. 280-1), “o mínimo não é referido pela quantidade, e pode muito além do número ou da cifra mensurável. Tal mínimo é valor e não metrificação, (...) não é menos nem é ínfimo. É um conceito apto à construção do razoável e do justo ao caso concreto, aberto, plural e poroso ao mundo contemporâneo".

7 "resta evidente que não se pode mais conceber, à luz de tais premissas, que a relação jurídica seja representada por um feixe de obrigações que se projetam reciprocamente entre as partes que compõem a relação jurídica num contexto de colaboração e ainda com ligações externas por conta da necessária obediência à função social do contrato" (CATALAN, p. 113).

8 Cristiano Chaves de Farias e Nelson Rosenvald (2009, p. 11) apresentam boa síntese da uniformidade conceitual da relação jurídica obrigacional clássica, a saber: a) caráter transeunte (até mesmo porque não pode haver uma relação obrigacional perpétua, o que implicaria, como se pode extrair do seu conceito, uma verdadeira servidão humana); b) vínculo jurídico entre as partes (através do qual a parte interessada pode exigir da outra, coercitivamente, o adimplemento); c) caráter patrimonial (pois somente o patrimônio do devedor pode ser atingido, afastada a sua responsabilidade pessoal); d) prestação positiva ou negativa (pode ser uma conduta de dar, fazer ou não fazer). Pugnando por uma releitura da estrutura obrigacional clássica, à luz do princípio da boa-fé objetiva ver (GAGLIANO; PAMPLONA FILHO, 2005, p. 75-7). 
as vicissitudes inerentes à visão solidarista da relação obrigacional, que não mais se limita ao resultado da soma de débito e crédito, devendo abandonar tal posição estática ${ }^{9}$ para que o vínculo obrigacional seja visto como um processo de cooperação voltado para determinado fim.

Não se trata de alijar as partes de sua liberdade de ação, mas de conformar o seu comportamento com a dimensão social (NANNI In: NANNI, 2008, p. 297), pois ainda que se sofram alterações pontuais no percurso, não há perda na sua "identidade de base" (BECKER In: NERY JUNIOR; NERY, 2010, p. 365). Dentro dessa perspectiva, "a ideia de que o vínculo obrigacional abriga, além de um débito e de um crédito, vários elementos jurídicos, suscetíveis de tratamento diferenciado e dotados de um sentido global que os transcende" (BECKER In: NERY JUNIOR; NERY, 2010, p. 364-5), conforme será visto no item seguinte.

\section{A RELAÇÃ̃o JURÍDicA OBRIGACIONAL COMO PROCESSO}

Como visto, tradicionalmente a relação jurídica obrigacional sempre foi concebida como uma estrutura unitária que se limitava a disciplinar o direito do credor ao cumprimento da prestação, contraposto ao dever do cumprimento da prestação imposto ao devedor, entendimento que, em princípio, não abrange a possibilidade de se vislumbrar em qualquer um dos partícipes da relação obrigacional a posição simultânea de credor e devedor.

Pugnando pelo tratamento da relação obrigacional como um todo, e ressaltando com tal afirmativa toda a complexidade intraobrigacional, Clóvis do Couto e Silva (2006, p. 20) anota que "mesmo adimplido o dever principal, ainda assim pode a relação jurídica perdurar como fundamento da aquisição (dever de garantia), ou em razão de outro dever secundário independente".

Para o citado autor, os deveres anexos de conduta seriam divididos em deveres dependentes e independentes, sendo a razão do discrime a verificação de que alguns deles "são susceptíveis de ultrapassar o término da obrigação principal, de terem assim vida própria. Em razão dessa particularidade, podem ser acionados independentemente da prestação principal" (COUTO e SILVA, 2006, p. 96).

Dentro dessa perspectiva, os figurantes da relação jurídica obrigacional devem buscar o adimplemento satisfatório, que decorre de múltiplas faculdades e situações que

9 Gustavo Tepedino, Heloísa Barbosa e Maria Celina Bodin de Moraes (2004, p. 492) anotam que “ao mesmo tempo que as escolas do direito civil contemporâneo conclamam a historicidade e a relatividade de seus institutos, a Teoria geral das Obrigações continua a ser tratada, difusamente, da mesma forma acrítica com que se enfrentou o tema na codificação anterior. As obrigações constituir-se-iam, segundo o entendimento tradicional, na mais bemacabada expressão da racionalidade técnica do direito civil: uma regulação perene, definitiva". Como se verá a seguir, tal orientação não atende às necessidades da contemporaneidade. 
se desenvolvem de modo dinâmico ao longo de todo o iter da relação jurídica obrigacional, que passa a ser vista como um conjunto complexo de fases direcionadas a um fim que não se satisfaz apenas com o cumprimento do dever de prestar (HAICAL In: MOTA; $\mathrm{KLOH}, 2011$, p. 487).

Partindo-se de tal entendimento, analisa-se o cumprimento contratual pela sua função econômico-social e não apenas pelo objeto principal da obrigação, observando-se que a partir do contato social surgem deveres relacionados à esfera jurídica do outro contratante que variam conforme as peculiaridades da situação, razão pela qual

\begin{abstract}
os deveres anexos não consistem, portanto, em elementos da relação contratual existentes $a b$ initio, em numerus clausus e com um conteúdo fixo. A sua concretização depende da verificação de pressupostos variáveis que, à luz do fim do contrato, adquirem essa eficácia. E não só o seu aparecimento: também o seu conteúdo interno, intensidade e duração dependem das circunstâncias atuais. De certo modo, pode-se dizer que existem, potencialmente, desde o início e são atualizados à medida que se vão verificando as situações que põem em perigo a consecução do interesse no contrato. Sua fixação, portanto, somente é possível em um determinado momento temporal e sua existência independe da hipótese de sua violação, extinguindo-se com seu cumprimento ou com sua superação através de uma alteração das circunstâncias que determinaram o seu surgimento, o que os torna sem objeto (BECKER, 2010, p. 369).
\end{abstract}

Ensina Clóvis do Couto e Silva (2006, p. 64) que tais deveres gerais independem da vontade dos envolvidos e surgem do contato social já na fase das tratativas, antes da incidência de uma norma jurídica juridicizando o negócio celebrado entre as partes.

Deve-se então analisar a relação jurídica obrigacional em sua totalidade, visualizando-a como um conjunto completo de fases direcionadas a uma finalidade, que mesmo mantendo como cerne o dever de prestar (HAICAL, 2011, p. 448), não atingirá a sua finalidade somente pelo cumprimento desse dever, pois se passa a considerar a existência de outros deveres exigíveis dos figurantes dessa relação, que também deverão ser observados para que a satisfação seja completa.

Nessa transição de um paradigma estático para um modelo dinâmico da relação obrigacional, é necessária uma releitura da disciplina do direito obrigacional que não pode ser considerado mero estatuto do credor, pois, como anota Pietro Perlingieri (2008, p. 212), a obrigação não mais se identifica com o direito ou os direitos do credor, já que cada vez mais, se configura como uma relação de cooperação por meio da qual o sujeito ativo necessita adotar uma postura de colaboração para o adimplemento, de modo a superar qualquer concepção de submissão para permitir que o sujeito passivo se veja liberto do vínculo (FARIAS; ROSENVALD, 2009, p. 13). O referido autor prossegue sustentando que

A incidência constitucional se realiza de vários modos: não apenas na individualização dos conteúdos das cláusulas gerais, como a diligência, a boa-fé, a lealdade, o estado de necessidade, etc., mas sobretudo, na releitura orientada axiologicamente de toda a disciplina em que consiste a relação e, em particular, no controle de valor das ordens de interesses representadas pelo 
título (...) e na relevância que a peculiaridade deste último tem condições de produzir na estrutura formal da relação (PerLingieri, 2008, p. 211).

Cabe então analisar o plano da eficácia ${ }^{10}$ da relação jurídica obrigacional em toda a sua complexidade, identificando direitos e deveres primários, secundários e laterais.

\section{A COMPLEXIDADE E A EVOLUÇÃO DOGMÁTICA DOS DEVERES Laterais de CONDUTa no Plano da EFicácia da RELAÇão JURÍDICA OBRIGACIONAL}

Os direitos e deveres primários da relação jurídica obrigacional constituem seu cerne na medida em que estão relacionados ao núcleo da satisfação dos sujeitos de determinada relação jurídica, permitindo a distinção correta entre os tipos contratuais. Ao seu lado, gravitando numa relação de complementaridade, encontram-se direitos e deveres secundários ${ }^{11}$, de caráter acessório da prestação principal. Estes exercem função de garantia da plena realização dos interesses dos figurantes da relação obrigacional (interesse no cumprimento).

Entretanto, como afirmado anteriormente, a relação obrigacional vista como um processo exige a observância de outra espécie de deveres que não estão apenas relacionados ao estrito cumprimento da prestação. Trata-se dos deveres laterais ou anexos, por vezes denominados na doutrina nacional de colaterais (TOMASETTI, 1995, p. 16-7), instrumentais (SAVI In: TEPEDINO, 2005, p. 476) ou fiduciários (NORONHA, 2004, p. 79-81).

O desenvolvimento de tal categoria deve-se aos trabalhos de Hermann Staub e Heinrich Stoll no enfrentamento de dificuldades que existiam da aplicação do código

${ }_{10}$ Marcos Bernardes de Mello (2003, p. 169) esclarece que "tudo o que se passa no mundo jurídico, sem exceção, é consequência (eficácia) de fato jurídico. Nele nada ocorre sem que haja um fato jurídico em sua origem. Partindo dessa premissa, tem-se à evidência que a relação jurídica é, exclusivamente, efeito de fato jurídico, sendo conceito pertinente ao plano da eficácia". Destaca o autor quatro princípios fundamentais que regem as relações jurídicas, advertindo que a (1) intersubjetividade, (2) a essencialidade do objeto e a (3) correspectividade de direito e dever, pretensão e obrigação, ação e situação de acionado e exceção e situação de excetuado são essenciais, pois a sua ausência compromete a própria existência da relação jurídica. Já o (4) princípio da coextensão de direito, pretensão e ação não seria essencial, porque pode sofrer exceções sem afetar a existência da relação jurídica. Para aprofundamento do tema, consultar a obra Teoria do Fato Jurídico. Plano da Eficácia. São Paulo: Saraiva: 2003, p. 171 e seguintes.

${ }^{11}$ Há quem separe os deveres secundários em diversas espécies, distinguindo os deveres acessórios da prestação principal (função de garantia) daqueles deveres com prestação autônoma (relativos a uma falha do próprio programa obrigacional), que ainda se subdividiriam em deveres sucedâneos (indenização por perdas e danos em virtude de inadimplemento absoluto) ou deveres coexistentes com a prestação principal (indenização em virtude de mora). Pelo menos na experiência brasileira, elevar a classificação dos deveres da relação obrigacional a esse nível de refinamento causaria mais transtornos do que vantagens, não se atribuindo nenhuma utilidade, no campo pragmático, à adoção de tais subdivisões (Cf. HAICAL In: MOTA; KLOH, 2011, p. 491-2). 
civil alemão antes da lei de modernização em 2000. Pelas mãos desses dois juristas, surgiu a teoria da violação positiva do contrato, relacionada aos deveres de cumprimento, e o desenvolvimento dos deveres de proteção na relação jurídica obrigacional, influenciando fortemente toda a construção doutrinária e jurisprudencial na direção da ampliação do conceito de adimplemento obrigacional.

O tratamento dogmático dos deveres laterais de conduta ultrapassou a mera exigência de proteção dos figurantes e do seu patrimônio para exigir um comportamento voltado à obtenção da plena satisfação da obrigação, abrangendo deveres de informação (esclarecimento) e de lealdade, em cuja base de sustentação está a boa-fé.

O conteúdo dos deveres laterais de proteção está relacionado à exigência de que as partes evitem que sejam infligidos danos mútuos às suas esferas jurídicas. Por sua vez, os deveres laterais de esclarecimento obrigam as partes a se informarem mutuamente de todos os aspectos atinentes ao vínculo, aos quais devem ser somados os deveres de lealdade, impondo a elas a abstenção de qualquer comportamento que possa desequilibrar as prestações, como também a adoção de deveres de atuação positiva para garantir o mesmo objetivo (MENEZES CORDEIRO, 2011, p. 604-7).

Ponto importante para melhor compreensão da questão aqui posta é a distinção entre deveres de prestação e deveres de proteção, em especial quando se considera que os efeitos jurídicos de tais deveres não se restringem somente aos figurantes da relação obrigacional e por vezes são estendidos a terceiros ${ }^{12}$.

Mesmo que o contrato seja concluído sem nenhuma estipulação em favor de terceiro (pretensão à prestação), reconhece-se ao sujeito estranho à relação obrigacional pretensão à proteção. Como anota Gustavo Luís da Cruz Haical (In: MOTA; KLOH, 2011, p. 498), "o dever de prestação ancora-se na existência da relação obrigacional estabelecida, tendo seu suporte fático descrito na lei ou nos usos do tráfico quando estes são modelos jurídicos. Os deveres laterais, ao contrário, não possuem um conteúdo predeterminado, pois derivam da boa-fé objetiva"13.

12 SEGURO DE VIDA. PRAZO DE CARÊNCIA. SUICÍDIO NÃO PREMEDITADO. PRINCÍPIO DA BOA-FÉ. APLICABILIDADE DAS SÚMULAS 105/STF E 61/STJ. O planejamento do ato suicida, para fins de fraude contra o seguro, nunca poderá ser presumido. A boa-fé é sempre pressuposta, ao passo que a má-fé deve ser comprovada. A despeito da nova previsão legal, estabelecida pelo art. 798 do CC/02, as súmulas 105/ STF e 61/STJ permanecem aplicáveis às hipóteses nas quais o segurado comete suicídio. A interpretação literal e absoluta da norma contida no art. 798 do CC/02 desconsidera importantes aspectos de ordem pública, entre os quais se incluem a necessidade de proteção do beneficiário de contrato de seguro de vida celebrado em conformidade aos princípios da boa-fé objetiva e lealdade contratual (REsp 959.618/RS, Rel. Ministro SIDNEI BENETI, Rel. p/ Acórdão Ministra NANCY ANDRIGHI, TERCEIRA TURMA, julgado em 7/12/2010, DJe 20/6/2011).

${ }^{13}$ Ao tratar dos contratos com eficácia protetiva para terceiros, Pontes de Miranda (1984, p. 266) deixava clara sua natureza jurídica de negócios sem pretensão à prestação, muito embora reconhecesse que o terceiro seria titular das pretensões de diligência ou proteção. Ele ressaltava que a extensão seria da "eficácia protetiva". 
Em relação à intensidade da exigibilidade dos deveres que compõem a relação jurídica obrigacional vista como um processo, há de se notar diferenças marcantes entre os deveres de prestação (principais e secundários) e os deveres laterais de proteção, informação e lealdade. Estes não são prefixados em nenhuma espécie contratual, ao contrário dos deveres principais, que, como visto, definem a natureza e estrutura do vínculo jurídico entre as partes.

Mas não é só. Os deveres laterais são exigíveis durante todo o iter da relação obrigacional complexa, desde a fase pré-contratual - quando a relação jurídica entabulada entre as partes e baseada no contato social ainda não apresenta deveres de prestação, baseando-se precipuamente na confiança depositada pelos figurantes na conduta leal e honesta do outro -, passando pela fase de execução e desenvolvimento do negócio e perdurando após esta se extinguir pelo cumprimento dos deveres de prestação, já que se exige na fase pós-contratual que os figurantes assegurem a plena utilidade dos direitos adquiridos.

Tal perspectiva deve ter em conta que a complexidade da relação jurídica obrigacional não se resume à mera soma de seus elementos parcelares ${ }^{14}$. Dito de outro modo: a relação obrigacional vista como processo não é a simples reunião dos fatores que a integrem, pois o "feixe de relações é como todo, e não como soma" (PONTES DE MIRANDA, 1984, p. 283) ${ }^{15}$. Além disso, conforme advertem Cristiano Chaves e Nelson Rosenvald (2009, p. 14):

(...) a contemporânea concepção da obrigação como processo polarizado ao adimplemento não é capaz de apagar o mérito da teoria dualista. Afinal, mesmo que acertadamente reconhecida como relação jurídica global - sob o ângulo de sua complexidade -, a obrigação ainda é ferida em sua acepção estrita - sob o ângulo de relação simples - como um vínculo que assegura ao credor exigir uma prestação. Se esta é sua essência, nada melhor do que precisar a dicotomia débito/responsabilidade para compreender o cerne do processo obrigacional.

14 Para Mário Luiz Delgado Régis (In: FIUZA, 2008, p. 206), “a obrigação deve ser vista não apenas pela soma dos seus elementos constitutivos, mas como um processo, uma série de atos relacionados entre si, que se encadeiam e convergem em direção à satisfação dos interesses recíprocos do credor (em receber) e do devedor (em pagar) culminando com o adimplemento, que é a finalidade última de toda obrigação. O vínculo é apenas uma ordem de cooperação, formadora de uma unidade que não se esgota na soma dos elementos que a compõem. O vínculo passa a ter sentido próprio, diverso do que assumiria se se tratasse de pura soma de suas partes, de um compósito de direitos, deveres e pretensões, obrigações, ações e exceções. Considerado como um todo, o vínculo obrigacional não se altera ou modifica com certas alterações e modificações sofridas pelas partes. Por esse motivo, o adimplemento de um crédito determinado pode não extinguir, ou modificar, a relação jurídica. Em outras palavras, mesmo adimplindo o dever principal, ainda pode a relação jurídica perdurar como fundamento da aquisição (dever de garantia), ou em razão de outro dever secundário independente".

${ }^{15}$ Um exemplo, fornecido pelo próprio Pontes de Miranda, ajudará a esclarecer a afirmação: “(...) $O$ conceito, por exemplo, de relação jurídica compra-e-venda não é conceito de relação jurídica a que corresponda dívida de prestar a coisa, mais de cuidar da coisa até a entrega, mais de não descurar da proteção jurídica da coisa; e sim o conceito de relação jurídica em que tudo isso é intrínseco". 
Para Menezes Cordeiro (2011, p. 586), a complexidade intraobrigacional traduz a ideia de que o vínculo obrigacional abriga "não um simples dever de prestar, simétrico a uma pretensão creditícia, mas antes vários elementos jurídicos dotados de autonomia bastante para, de um conteúdo unitário, fazerem uma realidade composta". Razão pela qual o autor sustenta que na reconstituição do conteúdo desta não se deve "estudar $e$ alinhar os elementos que a componham; antes é de partir do todo para as partes" (MENEZES CORDEIRO, 2011, p. 590).

Por esse motivo, Judith Martins-Costa (In: TEIXEIRA, 2003, p. 8-9) aponta a necessidade de "descer do plano das abstrações ao terreno rico e multiforme do concreto", destacando a necessidade de ultrapassagem do exame puramente externo da relação obrigacional em direção a uma análise interna, vale dizer, centrada na noção de adimplemento (TEPEDINO; BARBOSA; MORAES, 2004, p. 493) ${ }^{16}$, aqui compreendido como atuação concreta do programa obrigacional, levando-se em conta a concretude das circunstâncias nas quais se desenvolve a relação.

Por tal razão, os deveres derivados da boa-fé ordenam-se, assim, em graus de intensidade, dependendo da categoria dos atos jurídicos a que se ligam (COUTO e SILVA, 2006, p. 37), não sendo possível uma sistematização uniforme ou a elaboração de listas taxativas com descrição precisa de seus conteúdos, tamanha é a sua diversidade (DANTAS JUNIOR, 2008, p. 163).

\section{DEVERES LATERAIS OU DEVERES GERAIS DE CONDUTA?}

Fica bem evidente, da digressão acima, que a terminologia empregada pelos diversos autores para situar o fenômeno da relação jurídica obrigacional complexa não é unívoca. Ao anotar que toda obrigação recebe seu caráter distintivo pelo dever primário de adimplemento, Paulo Luiz Netto Lôbo sustenta que seu conteúdo total compreende deveres de conduta mais ou menos amplos. Destaca o autor, fazendo referência ao pensamento de LARENZ, que existe variada e farta terminologia para definir aqueles deveres que excedem do próprio e estrito dever de prestação, comumente denominados secundários, complementares, acessórios, conexos, laterais ou anexos (LÔBO, 2011, p. 73) ${ }^{17}$.

16 Os autores sustentam que a contemporaneidade requer uma análise "não mais centrada no método tradicional e que percebe a relação obrigacional tão-somente como um vínculo estruturado sobre dois pólos, ligados pelos co-respectivos direitos e deveres, ou seja, voltada para a descrição dos seus elementos constitutivos, visualizados in abstracto: os sujeitos (credor e devedor), o objeto (a prestação, o dar, fazer ou não fazer), os requisitos legais e os elementos acidentais, quando ocorrentes" (p. 493).

17 O autor prefere denominar de "acessórias" as obrigações não autônomas que existem em função da obrigação principal, citando como exemplos a fiança, a garantia de evicção e a responsabilidade por vício do produto ou do serviço (p. 74). 
Se no início da elaboração de tal teoria a concepção clássica desses deveres de conduta só os enxergava como derivados do dever primário de adimplemento e imputáveis apenas ao devedor, a evolução do direito e, em especial, a metodologia do direito civil constitucional que vem sendo empregada em nosso país nas últimas duas décadas, alçou alguns desses deveres ao status de deveres gerais de conduta, na medida em que se impõem tanto ao devedor quanto ao credor e, em determinadas circunstâncias, a terceiros (LÔBO, 2011, p. 74).

Sobre esse tema, explica Paulo Luiz Netto Lôbo (2011, p. 74-6) que

Esses deveres não derivam da relação jurídica obrigacional, e muito menos do dever de adimplemento; estão acima de ambos, tanto como limites externos ou negativos, quanto como limites internos ou positivos. Derivam diretamente dos princípios normativos e irradiam-se sobre a relação jurídica obrigacional e seus efeitos, conformando e determinando, de modo cogente, assim o débito como o crédito. Os deveres gerais de conduta exigem interpretação de seus efeitos e alcances diretamente conjugada aos dos princípios de onde promanam. A compreensão de uns implica a dos outros (...) Os deveres gerais de conduta, ainda que incidam diretamente nas relações obrigacionais, independentemente da manifestação de vontade dos participantes, necessitam de concreção de seu conteúdo, em cada relação, considerados o ambiente social e as dimensões do tempo e do espaço de sua observância ou aplicação. Essa é sua característica, razão por que são insuscetíveis ao processo tradicional de subsunção do fato à norma jurídica.

Para o referido autor, em nosso sistema jurídico seria possível definir como dever geral de conduta (a) o dever de boa-fé objetiva nas obrigações; (b) o dever de realização da função social das obrigações; (c) o dever de equivalência material das prestações; (d) o dever de equidade; (e) o dever de informar e (f) o dever de cooperar. Trata-se de postura inovadora em nossa experiência jurídica, uma vez que os autores nacionais costumam negar autonomia própria para os deveres de cooperação e informação, situando-os no mesmo espaço da boa-fé.

Paulo Luiz Netto Lôbo (2011, p. 90) explica que o direito à informação e o correspectivo dever de informar "têm raiz histórica na boa-fé, mas adquiriram autonomia própria, ante a tendência crescente do Estado social de proteção ou tutela jurídica dos figurantes vulneráveis das relações jurídicas obrigacionais" ${ }^{18}$.

No Código de Defesa do Consumidor é que se encontrou o substrato para seu desenvolvimento, lastreado nos requisitos da adequação, suficiência e veracidade. Adequação não se refere apenas ao conteúdo da informação, mas também à forma de divulgação (v.g., os meios de comunicação utilizados), enquanto a suficiência relacionase com a completude, vale dizer, a integralidade da informação sem omissão de referências não vantajosas para o fornecedor do produto ou serviço, como, por exemplo, eventuais consequências danosas da sua utilização.

18 Sobre o tema ver também (ALBUQUERQUE, 2006, p. 100-102). 
Exige-se ainda que a informação corresponda às reais características do produto ou do serviço e que seja cognoscível, ou seja, o consumidor precisa poder compreender a informação que lhe está sendo disponibilizada, não sendo suficiente para a eficácia do negócio o simples consentimento, uma vez que este se situa no plano da validade e não no plano da produção dos efeitos desejados pelas partes.

Ainda pugnando pela autonomia em relação ao dever geral de boa-fé, Paulo Lôbo (2011, p. 94-5) destaca que o dever de cooperação tem seu fundamento no princípio constitucional da solidariedade, razão pela qual não se limita ao espaço da relação interindividual, ultrapassando a qualificação de "dever lateral" de conduta, não devendo ser visto como mero efeito secundário dos deveres acessórios, em atenção ao compromisso valorativo do texto constitucional.

A categoria dos "deveres gerais de conduta" não foi estruturada para retirar importância da evolução doutrinária que refinou a noção da obrigação como processo, um todo orgânico dividido em deveres principais, secundários e laterais. Apresenta-se, destarte, como mais um passo desse desenvolvimento doutrinário, transcendendo a relação jurídica obrigacional, com reflexos importantes no campo da responsabilidade civil, conforme será tratado mais adiante.

Esta proposta de analisar a relação obrigacional buscando especializar outras categorias além da boa-fé também serve para refletir sobre a onipresença dela nas obras que tratam da matéria. Já se alcançou maturidade para refinar tal categoria, buscando novos desdobramentos no interesse do ótimo adimplemento.

No entanto, uma advertência se faz necessária. Os conceitos de "dever lateral" e "dever geral de conduta" não são excludentes e devem coexistir no sistema, como instrumentos úteis à agenda do direito civil constitucional. Um exemplo ajudará a compreensão de tal afirmação. Não é todo dever de informar que deve ser alçado à condição de dever geral de conduta, pois é possível encontrar no Código Civil várias situações nas quais o direito à informação é tratado como mero dever acessório da prestação obrigacional (v.g., arts. $569^{19}, 686^{20}$ e $864^{21}$ ).

Importante perceber que os deveres gerais de conduta, vinculados diretamente aos princípios, ultrapassam a função estrutural de auxiliares do adimplemento (LEONARDO,

19 Art. 566: "o locador é obrigado: (...) III - a levar ao conhecimento do locador as turbações de terceiros, que se pretendam fundadas em direito".

${ }^{20}$ Art. 686: "a revogação do mandato, notificada somente ao mandatário, não se pode opor aos terceiros que, ignorando-a, de boa-fé com ele trataram; mas ficam salvas ao constituinte as ações que no caso lhe possam caber contra o procurador".

${ }^{21}$ Art. 864: “tanto que se possa, comunicará o gestor ao dono do negócio a gestão que assumiu, aguardandolhe a resposta, se da espera não resultar perigo". 
2005, p. 104-5). Ao mesmo tempo, atuam como fonte e baliza de conformação no exercício de distintas posições jurídicas (CATALAN, 2011, p. 141). Afinal, como consequência do marco teórico aqui adotado, pode-se afirmar que "quem contrata não mais contrata tão só o que contrata" (FACHIN In: TEPEDINO, 2008, p. 458), razão pela qual é possível sustentar que "ainda que ignorados pelos contratantes, os deveres sob análise podem assumir dimensão negativa, impedindo a invasão arbitrária da intimidade, ou positiva, ao facilitar, por exemplo, o adimplemento" (CATALAN, 2011, p. 141).

O dever de realização da função social das obrigações atua como limite positivo que conforma todo o tráfego jurídico interparticulares, embora não esteja explicitado no texto de nossa Lei Maior. Exprime o comando de que os interesses individuais devem ser exercidos sem conflito com os interesses sociais, sempre que estes se apresentarem.

Há quem vislumbre em tal dever apenas uma mitigação do clássico princípio da relatividade dos efeitos do contrato, cuja aplicação estaria adstrita a situações em que terceiros estivessem sendo prejudicados pelo que foi pactuado. A função social estaria, neste prisma, relacionada a consequências meramente externas, não surtindo nenhum efeito na relação direta entre os contratantes ${ }^{22}$.

Nada obstante, prefere-se filiar à corrente que busca a funcionalização do princípio da solidariedade por meio do dever de realizar função social do contrato, perspectiva que prescreve compromissos em prol da comunidade, não só impondo limites, mas às vezes restringindo a própria possibilidade de contratar, com reflexos na responsabilidade contratual ${ }^{23}$.

Cada um dos deveres gerais aqui mencionados mereceria, por si só, um estudo específico, o que ultrapassa os objetivos deste trabalho. Buscou-se apenas contribuir para o debate e reflexão em torno de temas fundamentais para um modelo de interpretação que cada vez mais se utiliza de conceitos abertos na busca de fundamentação para o enfrentamento de questões cada vez mais complexas e casuísticas permeiam nosso cotidiano forense.

${ }^{22}$ Humberto Theodoro Júnior (2003, p. 37/40), que sustenta não ser razoável "suscitar desvio de função social quando a deslealdade de um contratante prejudicar os interesses apenas do outro". A solução para os casos de abuso interindividual ficaria adstrita ao campo da boa-fé objetiva, sendo legitimado para buscar tutela jurídica do Estado apenas o lesado.

${ }^{23}$ Neste sentido, o parágrafo único do art. 2.035 do Código Civil, norma de ordem pública, prescreve que "nenhuma convenção prevalecerá se contrariar preceitos de ordem pública, tais como os estabelecidos por este Código para assegurar a função social da propriedade e dos contratos". Tal dispositivo aplica-se inclusive aos atos jurídicos constituídos antes da entrada em vigor do CC/02, no que concerne aos seus efeitos, produzidos após a vigência deste. 


\section{REFERÊNCIAS}

ALBUQUERQUE, Fabíola Santos. O princípio da informação à luz do código civil e do código de defesa do consumidor. In: BARROSO, Lucas Abreu (Org.). Introdução crítica ao código civil. Rio de Janeiro: Forense, 2006. p. 100-102.

BECKER, Anelise. Elementos para uma teoria unitária da responsabilidade civil. In NERY JUNIOR, Nelson. NERY, Rosa Maria de Andrade (Org.). Responsabilidade Civil. Doutrinas Essenciais, Teoria Geral, v. I. São Paulo: Editora Revista dos Tribunais, 2010, p. 353 a 372.

CATALAN, Marcos Jorge. A morte da culpa na responsabilidade contratual. São Paulo: FDUSP, 2011. 347f. Tese (Doutorado em Direito), Faculdade de Direito da Universidade de São Paulo, 2011.

COUTO E SILVA, Clóvis V. A obrigação como processo. Rio de Janeiro: FGV, 2006.

DANTAS, JR., Aldemiro Rezende. Teoria dos Atos Próprios no princípio da Boa-fé. Curitiba, Juruá, 2008.

DELGADO, Mário Luiz; ALVES, Jones Figueiredo (Coord.). Novo Código Civil: Questões Controvertidas. São Paulo: Método, 2003. vols. 1 a 5.

FACHIN, Luiz Edson. Contratos na ordem pública do direito contemporâneo. In: TEPEDINO, Gustavo; FACHIN, Luiz Edson (Coord.). O direito e o tempo: embates jurídicos e utopias contemporâneas. Rio de Janeiro: Renovar, 2008.

. Estatuto Jurídico do Patrimônio Mínimo. 2. ed. Rio de Janeiro: Renovar, 2006.

FARIAS, Cristiano Chaves de. Direito das Obrigações. 4. ed. Rio de Janeiro: Lumen Juris, 2009.

FIUZA, Ricardo. Código Civil Comentado. 6.ed. São Paulo: Saraiva, 2008.

GaGlianO, Pablo Stolze; PAMPlOna FILHO, Rodolfo. Novo Curso de Direito Civil; Contratos. v. IV. São Paulo: Saraiva, 2005.

GOMES, Orlando. Contratos. Rio de Janeiro: Forense, 2004.

GONÇALVES, Carlos Roberto. Direito Civil Brasileiro; Teoria Geral das Obrigações, v. II, 6.ed. São Paulo: Saraiva, 2009.

LÔBO, Paulo Luiz Netto. Direito Civil: Contratos. São Paulo: Saraiva, 2011.

. Obrigações. São Paulo: Saraiva, 2011.

MARTINS-COSTA, Judith. Comentários ao Novo Código Civil. Do Direito das Obrigações. Do Adimplemento e da Extinção das Obrigações. In: TEIXEIRA, Sálvio de Figueiredo (Coord.). v. V, t. I. Rio de Janeiro: Forense, 2003.

MELLO, Marcos Bernardes de. Teoria do fato Jurídico: Plano de Eficácia. São Paulo: Saraiva, 2003.

. Teoria do Fato Jurídico. Plano da Existência, 14.ed. São Paulo: Saraiva, 2007

MENEZES CORDEIRO, António Manuel da Rocha. Da boa fé no direito civil. $2^{\text {a }}$ Reimpressão. Coimbra: Almedina, 2001.

MONTEIRO, Washington de Barros. Curso de direito civil: parte geral. 39. ed. Atualiz. Ana Cristina de Barros Monteiro Pinto. São Paulo: Saraiva, 2003. v.1 e v. 4

MOTA, Maurício; KLOH, Gustavo. Transformações Contemporâneas do Direito das Obrigações. Rio de Janeiro: Elsevier, 2011. 
NANNI, Giovanni Ettore. (Coord.). Temas Relevantes do Direito Civil Contemporâneo. São Paulo: Atlas, 2008.

NERY JÚNIOR, Nelson. Contratos no Código Civil. In: FRANCIULLI NETTO, Domingos et al. (Coord.). O novo Código Civil: estudos em homenagem ao Professor Miguel Reale. São Paulo: LTr, 2003.

NERY JÚNIOR, Nelson; NERY, Rosa Maria de Andrade. Código Civil e legislação extravagante. 2.ed. São Paulo: RT, 2003.

NERY, Rosa Maria de Andrade (Coord.). Função do Direito Privado no atual momento histórico. São Paulo: RT, 2006.

NORONHA, Fernando. Direito das Obrigações. 3.ed. São Paulo: Saraiva, 2010.

PEREIRA, Caio Mário da Silva. Instituições de direito civil. 20. ed. Atualiz. Maria

PERLINGIERI, Pietro. O Direito Civil na legalidade constitucional. Edição brasileira organizada por Maria Cristina De Cicco. Rio de Janeiro: Renovar, 2008.

. Perfis do Direito Civil: introdução ao Direito Civil Constitucional. Trad. Maria Cristina De Cicco. 2.ed. São Paulo: Renovar, 2002.

PONTES DE MIRANDA, Francisco Cavalcanti. Tratado de Direito Privado. São Paulo: Revista dos Tribunais, 1958. vol. XXV.

. Tratado de Direito Privado: Parte Geral. Atualiz. Vilson Rodrigues Alves. Campinas:

Bookseller, 2000. t.5.

. Tratado de Direito Privado. t. XXVI. São Paulo: Revista dos tribunais, 1984.

. Tratado de Direito Privado. t. LIII. São Paulo: Revista dos tribunais, 1984.

RIZZARDO, Arnaldo. Contratos. Rio de Janeiro: Forense, 2007.

RODRIGUES, Sílvio. Direito Civil. Dos contratos e das declarações unilaterais da vontade.

São Paulo: Saraiva, 2002.

SAVI, Sérgio. Inadimplemento das obrigações, mora e perdas e danos. In: TEPEDINO, Gustavo (Coord.). Obrigações: estudos na perspectiva civil-constitucional. Rio de Janeiro: Renovar, 2005.

TEPEDINO, Gustavo. (Coord.). Obrigações. Estudos na perspectiva civil-constitucional. Rio de Janeiro: Renovar, 2005.

TEPEDINO, Gustavo. Código Civil interpretado: Parte Geral e Obrigações. Rio de Janeiro: Renovar, 2004. v.1 e 2.

TOMASETTI JUNIOR, Alcides. As relações de consumo em sentido amplo na dogmática das obrigações e dos contratos, Revista de Direito do Consumidor, São Paulo, n. 13, p. 12-17, jan./mar. 1995.

VARELA, J. M. Antunes. Direito das Obrigações. Rio de Janeiro; Forense, 1977. 